https://doi.org/10.24201/aap.2021.328

INFORME

\title{
La pandemia y otros males: Filipinas en 2020
}

\section{The Pandemic and Other Ills: The Philippines in 2020}

\author{
MARIA ORTUOSTE \\ https://orcid.org/0000-0002-9800-838X \\ Universidad del Estado de California, East Bay, Estados Unidos
}

Recepción: 16 de noviembre de 2020

Aceptación: 23 de noviembre de 2020

Resumen: Filipinas no sólo sufre por la pandemia, sino por las condiciones políticas y económicas subyacentes que amenazan la seguridad humana. La administración de Duterte consolidó su poder institucional y creó una telaraña de redes políticas en todo el país para asegurar su liderazgo. Es necesario resucitar el sistema de salud para lidiar con la pandemia. La economía depende de remesas y de la tercerización de procesos de negocio, que no son las mejores bases para el desarrollo sostenido y equitativo. En términos de política exterior, Filipinas simplemente cambió una dependencia por otra y no ha obtenido grandes ganancias de su política relativa a China. La Ley Antiterrorista es sólo un ejemplo más del descenso del país a la dictadura. La región de Mindanao, que acaba de adquirir su autonomía, tuvo un comienzo desfavorable, mientras que la herida sigue viva entre los ciudadanos de Marawi. El hashtag \#OustDuterteNow [DerrocarADuterteAhora] ha sido tendencia a pesar de los altos índices de aprobación del presidente. Sólo puede concluirse que la seguridad humana no es, ni será, una prioridad para la actual administración.

Palabras clave: Filipinas; seguridad humana; covid-19; política interior; política exterior. 


\begin{abstract}
The Philippines suffers not only from the pandemic but from underlying political and economic conditions that threaten human security. The Duterte administration consolidated institutional power and created a cobweb of political networks across the country to ensure his legacy. The healthcare system needs to be resuscitated to deal with the pandemic. The economy relies on remittances and business process outsourcing which are not the best foundations for sustained and equitable development. In foreign policy, the Philippines simply traded one dependence for another, and has not realized substantial gains from its China policy. The Anti-Terror Law is just one more example of the country's descent into dictatorship. The newly-autonomous region in Mindanao has had an inauspicious start, while the citizens of Marawi continue to hurt. \#OustDuterteNow has been trending despite Duterte's high approval ratings. One can only conclude that human security is not, and will not be, a priority of the current administration.
\end{abstract}

Keywords: Philippines; human security; Covid-19; domestic politics; foreign policy.

\title{
FILIPINAS Y LA SEGURIDAD HUMANA
}

El 2020 no fue un año amable con los filipinos. De hecho, incluso podría decirse que la existencia humana se ha vuelto un lujo que muy pocos pueden permitirse. La pandemia y la desastrosa guerra contra las drogas no han evitado los juegos políticos, la incompetencia burocrática y la corrupción a las que están acostumbrados. De hecho, la pandemia parece estar contribuyendo a las maniobras del presidente Rodrigo Duterte para consolidar su poder y su legado, así como para allanarle el terreno a sus herederos. Las violaciones a los derechos humanos perpetradas por esta administración le han ganado el oprobio internacional y sus políticas económicas no han beneficiado a los más vulnerables. Aunque la Región Autónoma de Bangsamoro del Mindanao Musulmán (RABMM) se creó hace muy poco, ya ha tenido que lidiar con diversos desafíos por actos terroristas. La administración no ha logrado cosechar los frutos económicos que esperaba de su política de mitigación para con China. De hecho, esta última simplemente amplió su presencia en el Mar Occidental de Filipinas, al 
tiempo que mantuvo un control férreo sobre la ayuda para el desarrollo que había prometido. Por último, se sigue reprimiendo cualquier forma de disenso a través de medidas jurídicas, presiones económicas, campañas de desinformación y violencia. El presente artículo analiza los sucesos más relevantes de 2020 en lo relativo a la seguridad humana. Asimismo, aborda las problemáticas y los desafíos que se espera que perduren en 2021.

\section{CONSOLIDACIÓN DEL PODER Y LAS REDES POLÍTICAS}

Si bien la democracia filipina siempre ha tenido fallas, 2020 mostró el grado al que la administración de Duterte la ha deteriorado.

\section{¿Tres poderes de gobierno o sólo uno?}

Los tres poderes del gobierno están en manos de los aliados políticos de Duterte. Su partido, el PDP-Laban, controla la mitad del Senado, que está conformado por 24 miembros, y podría ganar los votos de senadores moderados e independientes, dependiendo del tema en cuestión. En la Cámara de Diputados, el PDP-Laban y sus aliados tienen una "supermayoría”, con 197 escaños de un total de 303. Ello aseguraría la continuidad de sus políticas, la aprobación de nuevas leyes como la reinstitución de la pena de muerte, y la posibilidad de hacer modificaciones a la Constitución.

Gran parte de quienes componen el gabinete actual de Duterte tiene vínculos personales cercanos con él, le han demostrado lealtad o comparten su abordaje punitivo del Estado de derecho. Varios de los integrantes del gabinete también sirvieron en las administraciones de Joseph Estrada y de Gloria Macapagal Arroyo. Algunos son ricos empresarios o descendientes de magnates y 16 son oficiales del ejército en retiro que sirvieron en Mindanao.

La Suprema Corte también se encuentra comprometida. Tras la controvertida destitución de la ex ministra presidente Maria Sereno, Duterte ha logrado llenar la Corte, nombrando a 12 de los 15 ministros que la conforman en un lapso de tres años. Dos de los nuevos ministros son oriundos de Davao, tres se graduaron de la Facultad de Derecho de San 
Beda, el alma mater de Duterte, y se sabe que otros tres comparten la postura estricta del presidente contra las drogas ilícitas.

Por supuesto, esto no significa necesariamente que no habrá desacuerdo alguno. Algunos senadores de la oposición han criticado tanto la administración de Duterte que éste los acusó de sedición. En septiembre, el pleno de la Suprema Corte "negó por unanimidad una solicitud para obtener las Declaraciones de Activos, Pasivos y Patrimonio neto (DAPPN) del ministro Marvic Leonen”, el tercero con mayor antigüedad de la Corte. El abogado Larry Gadon realizó la solicitud, y utilizó la misma táctica para facilitar la destitución de la ministro presidente Sereno. Sin embargo, una diferencia clave es que la Procuraduría General apoyó la petición de Gadon.

El conflicto radica precisamente ahí: si los tres poderes del gobierno están ocupados por aliados de Duterte y funcionarios que él mismo nombra, es prácticamente un hecho que obtendrá lo que desea. Incluso si se da espacio para la capacidad agentiva humana, los antecedentes de estos funcionarios y los legisladores aliados no inspiran confianza. Existen serios conflictos de interés e incluso se ha acusado a algunos de los funcionarios de soborno y actos de corrupción. ${ }^{1}$ Otros aliados de Duterte son conocidos por crear o implementar políticas controvertidas, como el nuevo senador Ronald "Bato" de la Rosa, o bien han sido acusados de fraude electoral. ${ }^{2}$

\section{Familia y redes políticas}

A pesar de sus bravatas contra las dinastías políticas, Duterte ha demostrado gran habilidad para manipular la política filipina, donde los pobres están "incrustados en redes de voto basadas en el parentesco, las relaciones personales y el intercambio de bienes y servicios con líderes locales que actúan como guardias electorales, pero que también ayudan a las

\footnotetext{
${ }^{1}$ Entre éstos figuran el actual titular de la Secretaría de Obras Públicas y Carreteras (SOPC), que anteriormente era legislador y es hijo de un desarrollador de bienes raíces; el secretario de Salud, cuyos hijos operan compañías que tienen contratos con el gobierno, y el actual procurador general, a quien se investigó por no ceder sus activos en una agencia de seguridad propiedad de su familia. Al menos cinco de los senadores recién electos han enfrentado cargos de corrupción: Cynthia Villar, Bong Revilla, Lito Lapid, Christopher "Bong” Go, quien ha sido la mano derecha de Duterte durante mucho tiempo, y Imee Marcos, la hija del difunto dictador.

${ }^{2}$ De la Rosa fue el jefe de la Policía Nacional Filipina de 2016 a 2018, e implementó la brutal Guerra contra las drogas. El actual consejero de Seguridad Nacional estuvo involucrado en el caso de fraude electoral contra Macapagal-Arroyo en 2005 .
} 
comunidades de su clientela pobre" (Thompson 2016, 252). Duterte logró incorporar "redes de intermediarios locales" — alcaldes y líderes barangay — antes de su presidencia y durante la misma (Kenny 2019). A diferencia de políticos anteriores, Duterte posee redes que abarcan desde Mindanao hasta Luzón. Estos vínculos se superponen y se entrecruzan de tantas maneras que, más que una pirámide, su red parece una telaraña en cuyo centro se encuentra su familia y en la que Duterte toma todas las decisiones.

El presidente ha dado una dimensión nacional a su dinastía provincial. El hijo de Duterte, Paolo, obtuvo un escaño en el Congreso por el primer distrito de la ciudad de Davao, mientras que otros dos de sus hijos, Sara y Sebastian, son la alcaldesa y el vicealcalde de la ciudad, respectivamente. Durante unos dos años, Duterte ha planteado la idea de que Sara sea su sucesora en la presidencia. Ella ya tiene bastante influencia, e incluso consiguió los votos de suficientes miembros de la Cámara de Diputados para remplazar al presidente de la misma (M. Cruz 2020).

Las dinastías políticas siguen prosperando: hay alrededor de 163 familias en el Congreso, y al menos 18 familias de políticos tienen dos o más miembros en el Congreso (Bueza y Castro 2019). De los 160 diputados recién electos, "al menos 65 remplazaron a algún familiar" (Bueza 2019). La más fuerte de estas dinastías es la de los Marcos, que se encuentra en una buena posición para lanzar una campaña presidencial exitosa en 2022.

La promesa de Duterte de crear un sistema de gobierno federal aún goza del apoyo de funcionarios locales, aunque el presidente ha sido reservado al respecto. El Comité de Reformas a la Constitución de la Cámara de Diputados se encuentra considerando cuatro iniciativas de modificación que darían a los gobiernos locales más control sobre los ingresos y periodos de gobierno más prolongados (Atienza 2020). La Liga de Municipios de Filipinas (LMF) apoya estas propuestas, pero las audiencias se pospusieron para 2021 debido a la pandemia.

La enfermedad de Duterte en el mes de agosto causó que un grupo no gubernamental, el Comité Coordinador Ejecutivo Nacional-Alcalde Rodrigo Duterte (CCEN-ARD), “anunciara una 'Declaración Popular de Gobierno Revolucionario"”. El grupo buscó el apoyo del presidente, la policía y las Fuerzas Armadas, pero no tuvo éxito (R. Robles 2020b). 
Sin embargo, la administración de Duterte está fortaleciendo a los gobiernos locales de otras maneras. La Fuerza de Tarea Nacional para Terminar con el Conflicto Comunista Armado Local (FTN-TCCAL) propuso la creación de un Fondo de Desarrollo de Barangay por un monto de \$402 millones para financiar proyectos de infraestructura y sustento. Los fondos sólo se otorgarán si la FTN certifica que el barangay está libre de comunistas (Lagrimas 2020).

\section{RESPUESTAS A LA PANDEMIA}

Para finales de octubre de 2020, Filipinas ocupaba el vigésimo lugar mundial en número de casos confirmados de covid-19, con un total de 376 935, es decir, 330.57 casos confirmados por cada 100000 habitantes. Los casos activos ascendían a 39940 y la tasa de fatalidad era de $1.90 \%{ }^{3}$ El gobierno aplicó medidas similares a las de otros países: cuarentenas, asistencia económica y social y un intento por aumentar la capacidad de atención médica. Gran parte de esta asistencia entra en el término general "Programas de Asistencia Estructural" (PAE) que implementa la Secretaría de Bienestar Social y Desarrollo (SBSD), la de Trabajo y Empleo (STE), la de Comercio e Industria (SCI) y la de Agricultura (SA). La asistencia se proporcionó con transferencias de efectivo, ayuda alimentaria, prórroga o disminución de las rentas, acceso a préstamos con tasas de interés subsidiadas, subsidios a los salarios, reducción de requisitos normativos, ayuda en efectivo para los trabajadores filipinos en el extranjero (TFE), apoyo en efectivo para los trabajadores de la salud y apoyo para pequeñas y medianas empresas (World Bank Group 2020).

El Consejo Nacional para la Reducción y la Gestión de Riesgos de Desastre (CNRGRD) informa que 15 millones de familias recibieron la primera ronda de los PAE, cuyo costo ascendió a \$1 870 millones de dólares; mientras que 3.7 millones de familias recibieron la segunda ronda, con un valor de $\$ 544$ millones. ${ }^{4}$ El Consejo también reportó que el programa de la SBSD distribuyó un total de dos millones de artículos alimentarios familiares, 103684 artículos que no eran alimentos y asistencia por un total de $\$ 150000$ dólares a personas en situación de crisis. En una encuesta que realizó en septiembre, The Social Weather Stations

\footnotetext{
${ }^{3}$ Esto se basa en el Contador Mundial de Covid-19 de la Universidad Johns Hopkins y el Rastreador de Covid-19 de la Secretaría de Salud.

${ }^{4}$ National Disaster Risk Reduction and Management Council, National Task Force, Coronavirus Disease-2019, Situational Report No. 204, publicado el 22 de octubre de 2020.
} 
(SWS) [institución dedicada a la investigación social, N. de la T.] indicó que 71\% de los respondientes recibió ayuda en efectivo por un promedio de \$158.15, un monto superior al que recibieron en julio de 2020. La encuesta también encontró que los residentes de la zona metropolitana de Manila recibieron ayuda en efectivo por montos mayores en promedio, en comparación con los habitantes del resto del país. ${ }^{5}$

Sin embargo, la respuesta del gobierno a la covid-19 tiene problemáticas importantes. Apenas a mediados de marzo se declaró el estado de calamidad, pero el primer caso en el país se reportó el 30 de enero, seguido por la primera muerte por covid-19 fuera de China tres días después (ABS-CBN News 2020). Duterte y su secretario de Salud, Francisco Duque III, minimizaron la gravedad del virus. Los desacuerdos entre los médicos de la Fuerza de Tareas Interinstitucional sobre Enfermedades Emergentes (FTIEE) y los generales en retiro que encabezan la Fuerza de Tareas Nacional (FTN) causaron retrasos y respuestas inadecuadas. Se dice que la FTN se impuso sobre los médicos, incluso en la toma de decisiones sobre el rastreo de contactos como en la aplicación de pruebas y las instalaciones de atención médica (Ranada y Tomacruz 2020).

Los ex generales implementaron cuarentenas derivadas de las operaciones de contrainsurgencia. Con base en el nivel de riesgo de las ciudades o provincias ante la covid19, la FTN implementó cuatro tipos de cuarentenas comunitarias con diversas reglas relativas a los toques de queda, el movimiento de personas y vehículos y el tipo de actividades permitidas en la zona de cuarentena. Sólo los militares, los oficiales de policía y las personas autorizadas a salir de su residencia (PASR) que trabajaban en el sector sanitario o en negocios considerados esenciales podían trasladarse libremente sin necesidad de una autorización de viaje o de un permiso de traslado. Las personas varadas localmente (PVL) y los viajeros por emergencia (VE) podían solicitar estos documentos en su estación de policía local, pero sólo se les otorgaban si entregaban el certificado médico apropiado. El tamizaje médico sólo buscaba síntomas comunes como fiebre alta, y sí se aplicaron pruebas para detectar el virus causante de la covid-19. Para el 22 de octubre, el gobierno había establecido 3110 "puntos de control de cuarentena" bajo la supervisión del Escudo Covid de Fuerzas de Tarea

\footnotetext{
${ }^{5}$ Sesenta y siete por ciento de quienes recibieron ayuda en efectivo dijo que sus familias recibieron la ayuda una vez, pero sólo 33\% la recibió en dos ocasiones (sws 2020c).
} 
Conjuntas, compuesto por la Policía Nacional Filipina (PNF), las Fuerzas Armadas de Filipinas (FAF), la Guardia Costera Filipina y la Oficina de Protección contra Incendios.

Infortunadamente, era difícil entender los diferentes tipos de cuarentenas y no era raro ver que los oficiales de los puntos de control confrontaran repentinamente a las personas y que la policía las acosara (Olanday y Rigby 2020). Las cuarentenas han sido especialmente difíciles para los trabajadores de la economía informal, quienes en 2017 representaban 56\% del total de los empleados en Filipinas, es decir, 22.17 millones de personas (Gonzales 2018).

La asistencia económica y social también se retrasaron. La primera ronda de PAE se liberó enteramente dos meses después de la aprobación de la legislación de emergencia conocida como Bayanihan-1 (Rey 2020). En un estudio realizado a más de 74000 empresas en Filipinas, el Banco Mundial encontró que sólo "1 de cada 5 reportaron haber recibido apoyo del gobierno nacional o el local" (World Bank Group 2020, 6). ${ }^{6}$ El mismo estudio encontró que $27 \%$ de las empresas tuvo dificultades al solicitar asistencia, alrededor de $26 \%$ ni siquiera estaba al tanto de los programas de apoyo y el resto no recibió apoyo después de solicitarlo o bien no se les consideró candidatas para recibir la ayuda.

La segunda ronda de PAE redujo el número de beneficiarios calificados, de 17.8 millones a 8.7 millones. El gobierno no proporcionó la asistencia suficiente (o bien, ninguna asistencia) a los desempleados que ganaban un salario medio, a los trabajadores informales, a los campesinos ni a los trabajadores agrícolas ni a muchos TFE (Bisenio 2020). Sin embargo, el gobierno anunció en mayo que dará "oportunidades de empleo temporal" a aproximadamente un millón de trabajadores de la economía informal y que se les había otorgado subsidios temporales (Dreyer y Nygaard 2020).

El segundo gran problema fue el pequeño presupuesto que se asignó para hacer frente a la covid-19. El rastreador de políticas relativas a la covid-19 del Banco Asiático de Desarrollo muestra que, entre los países del Sureste Asiático, Filipinas tuvo los paquetes económicos más bajos en total, el menor gasto en covid-19 como porcentaje del PIB y el gasto per cápita más bajo (véase la tabla 1). Para el segundo semestre de 2020, Duterte afirmaba que el gobierno se estaba quedando sin dinero. Le debía a la Cruz Roja filipina \$19.25

\footnotetext{
${ }^{6}$ El Banco Mundial encuestó a 74031 empresas privadas de todo el país. Encuestaron a micro, pequeñas, medianas y grandes empresas que operan en los sectores agrícola, manufacturero y de servicios.
} 
millones, deuda que finalmente saldó, cuando suspendió temporalmente la aplicación de pruebas (Reuters Staff 2020b). Además, la Secretaría de Salud decidió que no se practicarían pruebas de detección de covid-19 a los filipinos que volvieran de "países de bajo riesgo", pero que éstos debían "seguir estrictamente las normas de salud mínimas y aprobar el tamizaje de síntomas" (Esguerra 2020d).

TABLA 1. Comparación de paquetes económicos totales para covid-19, países selectos del Sureste Asiático

\begin{tabular}{lccc}
\hline & $\begin{array}{c}\text { Paquete total en millones } \\
\text { de dólares }\end{array}$ & $\begin{array}{c}\text { Porcentaje del PIB } \\
(2019)\end{array}$ & $\begin{array}{c}\text { Paquete per cápita } \\
\text { en dólares }\end{array}$ \\
\hline Filipinas & $\mathbf{2 1 4 4 8 . 3 5}$ & $\mathbf{5 . 8 3}$ & $\mathbf{2 0 1 . 1 1}$ \\
Vietnam & 26503.12 & 10.12 & 277.40 \\
Malasia & 80776.57 & 22.73 & 2562 \\
Tailandia & 84091.79 & 15.96 & 1211 \\
Singapur & 92141.78 & 26.2 & 16341 \\
Indonesia & 115775.27 & 10.94 & 432.54 \\
\hline
\end{tabular}

FUENTE: Banco Asiático de Desarrollo: https://covid19policy.adb.org/policy-measures (actualizado el 19 de octubre de 2020).

Estas cifras son desconcertantes porque el PIB del país creció a un promedio anual de $6 \%$ entre 2010 y 2019 , y el presidente recibió facultades especiales para reasignar los fondos del gobierno bajo la ley Bayanihan para Sanar Unidos, o Bayanihan-1 (Magsino y Colcol 2020).

El problema más grave es que el sistema de salud de Filipinas está infradotado de recursos, no cuenta con equipamiento suficiente y tiene una distribución desigual en las regiones. Además no cuenta con suficientes profesionales de la salud. La tabla 2 muestra que, incluso en el "mejor escenario", Filipinas sólo cuenta con una fracción de las capacidades sanitarias necesarias para lidiar con la pandemia. 
TABLA 2. Capacidades sanitarias necesarias para el mejor escenario versus capacidades reales*

\begin{tabular}{cc}
\hline Mejor escenario posible para el IFED & Capacidades reales \\
\hline $\begin{array}{c}182000 \text { camas de hospital; 55 000 } \\
\text { camas de terapia intensiva }\end{array}$ & $\begin{array}{c}1940 \text { camas de terapia intensiva; } 13665 \\
\text { camas en aislamiento; 6 170 camas en } \\
\text { pabellón de covid-19 }\end{array}$ \\
30000 respiradores & 2068 respiradores (octubre de 2020) \\
88000 médicos; 118 000 enfermeras; & 40775 médicos; 90 308 enfermeras (2017) \\
11000 especialistas médicos & \\
$\begin{array}{c}4.4 \text { millones de conjuntos de equipo } \\
\text { de protección personal }\end{array}$ & \\
\hline
\end{tabular}

*El IFED (Instituto Filipino de Estudios de Desarrollo) lleva a cabo investigación y planeación económicas (Abrigo et al. 2020). Otras fuentes son el sitio web de la Secretaría de Salud y los datos correspondientes a 2017sobre médicos y enfermeras tomados de Dayrit et al. 2018.

El prolongado confinamiento no se aprovechó al máximo. El "Sistema de Comando Hospitalario Único" se lanzó apenas en agosto, cuando el número de casos de covid-19 se incrementó súbitamente de 93354 a 220819 en un solo mes, lo que representó una gran amenaza para el sistema hospitalario del país (Magsino 2020). La aplicación de pruebas se dificulta por la falta de instalaciones, aunque el país ahora cuenta con 140 laboratorios de pruebas, en comparación con los 66 que había en junio. Así, lograron aplicar la prueba a 4.7 millones de muestras acumulativas de aproximadamente 4.5 millones de personas, lo que representa sólo alrededor de 4\% de la población nacional, casi 107 millones de habitantes.

Sin embargo, quizá el mayor problema sea la escasez de profesionales de la salud. La Oficina de Epidemiología no pudo realizar un rastreo de contactos amplio porque su personal ya se encontraba lidiando con brotes de poliomielitis y sarampión (Ranada y Tomacruz 2020). Aunque "Filipinas produjo un promedio anual de 26000 enfermeras autorizadas de 2012 a 2016", unas 18 600, o 71.5\%, "se mudaron a otro país cada año durante el mismo periodo" (Lopez y Jiao 2020). La respuesta inmediata e irreflexiva de Duterte fue prohibir que el personal médico y de enfermería saliera del país para trabajar en el extranjero. ${ }^{7}$ Para compensar esta deficiencia, la Secretaría de Salud contrató temporalmente a profesionales de

\footnotetext{
${ }^{7}$ Al final, Duterte cedió y la Secretaría del Trabajo ha ido relajando las restricciones para permitir viajar a las personas que tienen contratos laborales pendientes (Reuters Staff 2020a).
} 
la salud que laboraban en hospitales de gobierno de diversas ciudades y provincias (Yee 2020) y amplió el horario de los empleados actuales, lo que aumenta su riesgo de exposición al virus. Dos importantes hospitales de gobierno cerraron temporalmente en agosto por este motivo (Ratcliffe 2020).

Aunque la administración de Duterte no causó esta crisis sanitaria, sus políticas no hicieron nada por mejorar el sistema de salud, sobre todo cuando los presupuestos asignados al sector comenzaron a disminuir en 2016 (IBON Media \& Communications 2020). La pandemia no detuvo los actos de corrupción en Philhealth, la aseguradora nacional, a cuyos miembros del Consejo se acusó de malversar \$581 000 dólares. El Secretario de Salud estuvo involucrado en ese escándalo, pero Duterte apoyó firmemente a su amigo, no obstante una resolución del Senado que llamaba a despedir al secretario por su incompetencia (Palatino 2020b). Las pugnas políticas por la presidencia de la Cámara de Diputados retrasaron las audiencias relativas al presupuesto de 2021, y la coalición mayoritaria se negó a cruzar sus límites ideológicos para apoyar iniciativas sensatas como la Iniciativa de la Cámara 6848, la "Ley de aplicación masiva de pruebas gratuitas de 2020", que propusieron los partidos opositores (Piedad 2020).

\section{CONSECUENCIAS ECONÓMICAS}

La pandemia causó el peor deterioro en la economía nacional en 20 años. El país perdió \$21 000 millones de dólares en los primeros 45 días del confinamiento y el PIB cayó 16.5\% en el segundo trimestre (A. Robles 2020; Dela Cruz y Morales 2020). En abril, la tasa de desempleo de Filipinas había llegado a un máximo histórico de 17.7\%, con 7.3 millones de personas desempleadas (Agcaoili 2020).

El Banco Asiático de Desarrollo (BAsD) proyecta que, para fines de 2020, la tasa de crecimiento del PIB de Filipinas será la segunda más baja del Sureste Asiático, $-7.3 \%$. En contraste, su tasa de desempleo será la más alta de la subregión, 18.5\%, lo que significa 
alrededor de ocho millones de desempleados (Agcaoili 2020), y su tasa de inflación alcanzará el 2.4 por ciento. ${ }^{8}$

Estas pérdidas no se sentirán de igual manera en todo el país. Las provincias más pobres están en Mindanao, así como el menor número de centros de salud. Antes de la pandemia, la brecha en los ingresos era grande. Los más ricos (el 10 decil) recibían 27.7\% de los ingresos totales, mientras que los más pobres (el $1^{\mathrm{er}}$ decil) percibían sólo $3.6 \%$ del total (PSA 2018). El Brookings Institute [Instituto Brookings] calculó que diez millones de filipinos vivirán en pobreza extrema, el sexto índice más alto del mundo (Mendiola 2020).

La problemática se exacerba por la naturaleza de la economía filipina, que se basa en "factores de crecimiento externos y temporales", como "las remesas y la inversión extranjera, especialmente para la tercerización de procesos de negocio (TPN) y la manufactura" (Lim 2020b). Un estudio del Overseas Development Institute [Instituto de Desarrollo de Ultramar] también demostró que Filipinas es el tercer país más vulnerable a la desaceleración económica de China, que puede esperarse que ocurra en 2020 (Raga y te Velde 2020).

\section{Dependencia de trabajadores filipinos en el extranjero}

En 2019 había alrededor de 2.2 millones de TFE en el mundo y representaban 11\% del PIB del país, gracias al envío de remesas con un valor de \$400 dólares per cápita (PSA 2020). Para el primer trimestre de 2020, las remesas ya se habían reducido $16.2 \%$, la peor caída en 18 años (Noble 2020). En el peor escenario, se calcula que las remesas descenderán alrededor de 20.2\% (Takenaka et al. 2020). La pandemia afectó de inmediato a los trabajadores recién desplegados y a los empleados del sector marítimo. En noviembre, alrededor de 523238 filipinos habían vuelto, 222000 de los cuales llegaron a sus provincias. ${ }^{9}$

Alrededor de $8.4 \%$ de los hogares filipinos dependen de las remesas internacionales, $21 \%$ de las cuales tienen como destinatarios a ciudadanos de la tercera edad. Se proyecta que el gasto familiar descienda entre $2.2 \%$ y 3.3\%, lo que deprimirá aún más la economía (Takenaka et al. 2020). Infortunadamente, al inicio de la pandemia los TFE no figuraron en la

\footnotetext{
${ }^{8}$ Véanse los indicadores económicos de Filipinas en http://www.adb.org/countries/philippines/economy

${ }^{9}$ NDRRMC covid-19 Situational Report No. 226. 13 de noviembre de 2020. Disponible en http://ndrrmc.gov.ph/ attachments/article/4036/NTF COVID19 SitRep No 226 as of 13Nov2020 12NN.pdf
} 
lista de candidatos a beneficiarios de asistencia financiera del gobierno. Aproximadamente 170000 de ellos solicitaron un pago único de \$197 dólares, pero sólo se le otorgó a 52000 personas (Depasupil 2020). Los economistas no esperan un alivio inmediato porque las economías caerán entre $6.7 \%$ y $10.2 \%$ para finales del año. ${ }^{10}$

\section{La apuesta por los POGO}

La administración de Duterte esperaba obtener beneficios económicos de los Operadores de Juegos de Azar Offshore en Filipinas (POGO, por sus siglas en inglés) pero ha sido difícil evaluar ese impacto. Se calcula que éstos podrían aportar a la economía desde \$1 870 millones hasta $\$ 11440$ millones de dólares. El último cálculo de trabajo es de $\$ 147$ millones, que representa sólo 0.04\% de la economía mundial (Newsdesk 2020; Rivas 2019; Gutierrez 2020). No obstante, la Oficina de Recaudación Interna (ORI) afirmó que "casi todos los POGO administrados por chinos están retrasados en el pago de sus impuestos sobre la renta y las franquicias por un monto aproximado de 50000 millones de pesos filipinos (\$988 millones de dólares)" (Heydarian 2020).

No se crearon los empleos prometidos, pues sólo 10\% de los empleados de los POGO son filipinos (Casayuran 2020). Alrededor de 250000 empleados chinos envían sus ingresos a través de remesas, de modo que esos ingresos también se pierden (San Diego 2019; Siu y Zheng 2018). Los POGO también han hecho que las rentas aumenten $150 \%$, lo que ha llevado a desalojos, y se da preferencia a los propietarios chinos por la prestación de cualquier servicio de apoyo, como el de restaurante (San Diego 2019).

Además hay otros costos económicos y sociales. Los POGO han fomentado la corrupción, sobre todo en la Oficina de Inmigración. Incluso una organización contra la delincuencia afirmó que el país "se está convirtiendo en un refugio para delincuentes y organizaciones criminales chinas" (A. Robles 2019). Estos delitos incluyen el trabajo forzado, el rapto y quizá incluso el tráfico de estupefacientes (Tupas 2020; Lim 2020a). La crítica pública llegó a un crescendo cuando Duterte clasificó a los POGO como comercios esenciales durante el confinamiento, mientras que pequeñas empresas propiedad de filipinos

\footnotetext{
${ }^{10}$ Asia (35\%), el Medio Oriente (27\%), Europa incluyendo la Federación Rusa (19\%) y Norteamérica (18\%) (Takenaka et al. 2020).
} 
tuvieron que cerrar (Heydarian 2020). Esto llevó a la introducción de una iniciativa anti-POGO que podía declararlos como ilegales (Mercado 2020).

Sin embargo, este tema podría ser debatible y académico. El gobierno chino también está tratando de cerrar algunos POGO por sus vínculos con el lavado de dinero. Debido a la pandemia, los centros de operación de los casinos en línea están limitados a 30\% de su capacidad original, de conformidad con las reglas sanitarias. Además, sólo 32 de 60 POGO autorizados han reiniciado operaciones (O’Connor 2020).

\section{Políticas económicas cuestionables y corrupción}

El país aún se está recuperando de los efectos de la Ley de Reforma Fiscal para la Aceleración y la Inclusión (LRFAI), que presionó significativamente a quienes tenían ingresos de nivel medio y también acentuó la pobreza de los grupos económicos vulnerables (Punongbayan 2019). El programa Build, Build, Build (B3) [Construir, construir, construir] gozó de gran publicidad pero no de éxito, aunque el gobierno informa que estos proyectos crearon alrededor de cinco millones de empleos entre 2017 y 2019 (PDI Editorial 2020). Sin embargo, probablemente se haya tratado de empleos pasajeros o temporales en la industria de la construcción, no de puestos permanentes. Los proyectos de infraestructura también han recibido críticas por ser demasiado costosos o por la falta de estudios de factibilidad para ellos (ASEAN Post Team 2019). La pandemia también se está aprovechando como una forma de acelerar la eliminación progresiva del jeepney, el principal medio de transporte público del país. La prohibición del transporte público ha causado el desempleo de 250000 conductores de jeepney y la pérdida de alrededor de $\$ 500$ dólares en ingreso mensual (McCarthy 2020). Sin embargo, el gobierno sólo ha proporcionado unos \$168 dólares en ayuda monetaria (Lalu 2020). Hay otras muchas ineficiencias, como las de la política monetaria, la rigidez de las normas de trabajo y posibles sanciones por parte de países donadores debido a violaciones a los derechos humanos (Chikiamco 2020). Además, cada año Filipinas perdía alrededor de "700 000 millones de pesos filipinos [\$14 700 millones de dólares], equivalente a un 20 por ciento de la dotación presupuestaria total del país, debido a la corrupción", lo que asciende a un total de \$29 000 millones de dólares en los últimos dos años. El ómbudsman adjunto, Cyril Ramos, indicó que el monto de los ingresos perdidos era 
"equivalente a 1.4 millones de viviendas para los pobres, asistencia médica para unos 7 millones de filipinos, o una reserva de arroz que podría durar más de un año" (Gagalac 2019).

\section{PolíticA EXTERIOR}

La problemática central de la política exterior filipina en 2020 fue el Mar de la China Meridional, particularmente sus relaciones con China, Estados Unidos y la Asociación de Naciones del Sudeste Asiático (ASEAN, por sus siglas en inglés). Al parecer, la administración ha comenzado a percatarse de las consecuencias negativas de las decisiones de política exterior que tomó en 2016, pero que ahora resulta sumamente difícil dar marcha atrás.

\section{La locura del pragmatismo}

Este año marca el cuarto aniversario de la victoria de Filipinas en su caso de arbitraje contra China. A pesar de que en un inicio la recepción fue tibia, varios actores han usado esta decisión como base para sus propios reclamos contra China (Vietnam, Malasia e Indonesia), o como una forma de criticar el ímpetu expansivo de China, como la note verbale conjunta que presentaron Francia, Alemania y el Reino Unido (CNN Philippines Staff 2020b).

Además, éste es el cuarto año en el que el gobierno chino ha prometido a Filipinas 9000 millones de dólares en inversiones y asistencia para el desarrollo. A la fecha sólo se han iniciado dos proyectos de infraestructura, y China sólo ha proporcionado 1000 de los 9000 millones de dólares que había prometido (Lee 2020; R. Robles 2019). Los planes para actividades conjuntas de exploración de gas y petróleo también se han retrasado (R. Robles 2020a).

Queda claro que la política pragmática de Duterte no ha beneficiado al país o incluso al Sureste Asiático de forma alguna. Desde 2016, China ha reclamado territorios, hostigado a la guardia costera, a buques navales y pesqueros, ingresado a las zonas económicas exclusivas (ZEE) de todos los países del litoral, e incluso ha hundido buques pesqueros. Además ha establecido dos regiones administrativas nuevas para reforzar su presencia militar en la zona (Huong y Pascoe 2020; Septiari 2020). Asimismo, ha establecido formidables 
fortificaciones militares en sus zonas ocupadas. Éstas contienen radares, equipo de comunicación, pistas de aterrizaje y hangares, así como sistemas de misiles tierra-aire y de misiles de crucero antibuques (AMTI 2020). En pocas palabras, China tiene la infraestructura necesaria para establecer una Zona de Identificación de Defensa Aérea.

La respuesta filipina no ha sido constante. Tanto el secretario de Relaciones Exteriores como el de la Defensa apoyan un orden basado en las reglas y fundado en el laudo de la Corte Permanente de Arbitraje (CPA) (Wong 2020). Teodoro Locsin Jr., el secretario de Relaciones Exteriores, declaró que Filipinas "reafirma [...] su cumplimiento del laudo [de la CPA] y su procuración sin posibilidad alguna de concesión o cambio”. Además, agregó que si los ejercicios militares de China llegaran a abarcar territorio filipino, "se respondería de 'la manera más severa"' (Esguerra 2020c). Sin embargo, cuando el gobierno chino insistió en que la decisión arbitral era "ilegal e inválida", el vocero de la presidencia, Duque, asumió un tono más conciliador diciendo que Filipinas sostendría su enfoque pacífico y diplomático en esta controversia, puesto que "no es posible procurar el cumplimiento" del laudo de la CPA (Gita-Carlos 2020).

\section{¿Demostración de fuerza o distracción de Estados Unidos?}

Asimismo, el gobierno de Estados Unidos pronunció sus declaraciones más fuertes sobre el Mar de la China Meridional, revirtiendo la política de no tomar partido que había sostenido durante la última década. El secretario de Estado, Mike Pompeo, afirmó que "Estados Unidos apoya a nuestros aliados y socios del Sureste Asiático en la protección de sus derechos soberanos a los recursos marinos, en congruencia con sus derechos y obligaciones consagradas en el derecho internacional" debido a las reivindicaciones "ilegales" de recursos marinos por parte de China (Pompeo 2020). A esto siguió la declaración del subsecretario de Estado, David Stilwell, en el sentido de que Estados Unidos “estamos decididos a proteger nuestros intereses vitales, así como los de nuestros aliados y amigos”, y que potenciará las “capacidades militares de los países implicados" (Stilwell 2020).

Si bien los motivos de Estados Unidos son sospechosos, queda claro que ésta es una oportunidad que no debe dejarse pasar. Infortunadamente, el principal mecanismo que puede emplearse es el Acuerdo sobre las Fuerzas Extranjeras (AFE), pero Filipinas dio su aviso 
formal para rescindirlo antes de junio de 2020, principalmente porque a Duterte no le agradó que Estados Unidos pusiera en lista negra a su confidente por violaciones a los derechos humanos relacionadas con la guerra contra las drogas. Los eventos que se sucedieron en 2020 - la agresión marítima de China y la exigencia pública de implementar una política más asertiva hacia esta última - pudieron haber contribuido a que Duterte cambiara de opinión, pero él no puede admitir su error públicamente. En lugar de ello, la administración ha cancelado la rescisión del acuerdo en dos ocasiones: en junio y en noviembre. En la primera ocasión, el Senado y otros funcionarios de gobierno filipinos hicieron un llamamiento colectivo a "una revisión por parte de diversas instancias" (R. Robles 2020c). En la segunda ocasión, el gobierno filipino quiso encontrar "un acuerdo enriquecido, más beneficioso y grato para ambas partes, más efectivo y duradero relativo al avance de nuestra defensa mutua" y "en reconocimiento agradecido" (R. Robles 2020c). Ahora, el gobierno tiene hasta mayo de 2021 para encontrar una solución que le ayude a guardar las apariencias.

El ejército filipino sostiene una relación bilateral institucionalizada con Estados Unidos desde hace casi 80 años y este último continuó brindando asistencia militar incluso durante la administración de Duterte. ${ }^{11}$ Como tal, el gobierno no emprendió medidas serias para buscar un aliado como Estados Unidos, dado que el ejército filipino sospecha fuertemente del gobierno chino. La administración de Duterte debe caminar una fina línea entre asegurar la confianza pública y el apoyo militar y defenderse de la presión económica de China.

\section{Un apoyo más amplio}

La asertividad de China también llevó a varios miembros de la ASEAN a pronunciar fuertes declaraciones. Duterte mencionó “incidentes alarmantes” en el Mar de la China Meridional, mientras que el primer ministro vietnamita "habló de 'acciones irresponsables y actos violatorios del derecho internacional' en referencia evidente a las actividades de China en la

\footnotetext{
${ }^{11}$ En 2019, la mayor fuente proveniente de Estados Unidos fue el Departamento de la Defensa, que desembolsó \$223 millones de dólares. Hasta mediados de 2020, éste ha otorgado \$15 millones de dólares, pero los principales proyectos son de la Agencia de Estados Unidos para el Desarrollo Internacional (USAID, por sus siglas en inglés) y del programa Food for Progress [Alimentos para el progreso], relacionados con la covid-19. Además, USAID ha otorgado \$5.6 millones de dólares para el Marawi Response Project [Proyecto de Respuesta Marawi]. USAID, Foreign Aid Explorer [Explorador de ayuda internacional]. Disponible en https://explorer.usaid.gov/cd/PHL?fiscal year=2020\&measure=Disbursements
} 
zona" (Koh 2020). En 2020, Indonesia envió una carta al secretario general de Naciones Unidas en la que indicaba que la línea de los nueve puntos de China carece de "fundamento jurídico internacional", pues se basa en derechos históricos, no en la Convención de las Naciones Unidas sobre el Derecho del Mar (CDM) (Inggas y Bechtel 2020).

\section{El error de cálculo de Duterte}

El abordaje "pragmático" de Duterte se basó en una visión simplista de que el poder militar siempre prevalece. Si bien China puede tener un gran poderío militar, la decisión de la CPA dio a Filipinas una firme base jurídica internacional para sus reivindicaciones sobre el Mar Occidental de Filipinas. Aunque la respuesta inicial al laudo fue tibia, ello no fue determinante de acciones futuras por otras partes. Filipinas pudo haber empleado este laudo como base para conformar una coalición que apoyara los esfuerzos del país por desarrollar un Código de Conducta en el Mar de la China Meridional que fuera sustancial y vinculante. Además, la decisión no tomó en cuenta el fracaso de la política de involucramiento constructivo con China de la ASEAN. Por último, la administración también subestimó el fuerte sentimiento antiChina de los filipinos, que, para julio de 2020, había caído a la categoría de "malo" según las encuestas, mientras que la confianza en Estados Unidos seguía siendo "buena” (Inquirer Research 2020).

\section{DERECHOS HUMANOS}

No sorprende el hecho de que la inseguridad, la violencia y la muerte siguen siendo los rasgos distintivos de la administración de Duterte. Sin embargo, 2020 parece haber traído consigo el apogeo de la brutalidad: la escala de las violaciones a los derechos humanos ascendió de manera significativa; se está silenciando rápidamente a activistas y ciertas organizaciones mediáticas, y, por último, se aprobó la Ley Antiterrorista para formalizar y legitimar las prácticas de la administración contra los derechos humanos, como calificar a los opositores de comunistas ("etiquetado rojo" o red-tagging), el acoso en línea, el hostigamiento físico y el homicidio. La pandemia simplemente le dio al gobierno otro motivo para castigar a las 
personas, incluso si no se les etiqueta de usuarios/traficantes de drogas, comunistas o terroristas.

\section{Drogas y cuarentenas}

La Agencia Antinarcóticos Filipina (AAF) reporta que unas 5856 personas han muerto en operativos policiales desde 2016. No obstante, los grupos defensores de los derechos humanos afirman que, si se añaden a la lista los homicidios extrajudiciales, la cifra de muertos total asciende a 25000 en los últimos cuatro años. La cuarentena facilitó la localización de los blancos. La organización Human Rights Watch, empleando datos del gobierno, calculó que cada mes desde diciembre de 2019 a marzo de 2020 murió un promedio de 26 personas, pero la cifra ascendió a 39 durante el confinamiento. Otros usuarios/traficantes de drogas se encuentran en reclusorios, sin esperanza alguna de tener un juicio expedito. El gobierno ha admitido que la tasa de congestión en los reclusorios fue de 534\% para 2020, lo que no sorprende si se considera que la AAF informó que se ha aprehendido a 256788 indiciados desde $2016 .^{12}$

La militarización de la cuarentena ha llevado al arresto de 186947 "violadores del toque de queda" y 5596 conductores de jeepney que siguieron operando sus vehículos de transporte público en contravención a las reglas de la cuarentena. La policía incluso aprehendió a 20 personas que simplemente estaban solicitando paquetes de alimentos (Marquez 2020). Entre el 17 de marzo y el 25 de julio, la Comisión Filipina de Derechos Humanos (CFDH) recibió 900 quejas de "presunta tortura o tratos, aprehensiones y detenciones inhumanas" (Cabato 2020). Además, las cuarentenas interrumpieron la entrega de ayuda por parte de las organizaciones humanitarias, tanto para los residentes como para los evacuados. Existen buenos motivos por los que la cuarentena filipina de 78 días se consideró "el confinamiento a causa del coronavirus más largo y estricto del mundo" (Olanday y Rigby 2020).

\footnotetext{
${ }^{12}$ Naciones Unidas, Asamblea General, Situation of Human Rights in the Philippines: Report of the United Nations High Commissioner for Human Rights, A/HRC/44/22. 29 de junio de 2020. Disponible en https://undocs.org/en/A/ $\mathrm{HRC} / 44 / 22$
} 


\section{Defensores del medio ambiente}

Desde 2016, alrededor de 113 defensores del medio ambiente han muerto asesinados, el doble que en los años 2012-2015 (Lalu 2019). Los activistas ambientales incluyen tanto a personas indígenas como no indígenas, y aunque los primeros representan a sólo 14\% de la población filipina, "representaron a una tercera parte de los defensores del medio ambiente víctimas de homicidio". ${ }^{13}$ Los pueblos indígenas, que quieren proteger sus terrenos ancestrales, se han enfrentado a compañías mineras, madereras y constructoras, a las que el ejército u organizaciones paramilitares apoyadas por el gobierno defienden, como las "Fuerzas de defensa de la inversión”. A muchos de estos defensores, al igual que los trabajadores humanitarios, se les tacha de comunistas y después se convierten en blanco de hostigamiento, y más adelante, de homicidio (Jha 2020).

\section{Silenciamiento de la expresión y el disenso}

En su informe de 2019, la ONG Freedom House afirmó que la libertad de prensa, de palabra y de expresión se están debilitando en el país y que se está restringiendo a los sindicatos y organizaciones similares. El análisis Freedom on the Net 2019 [Libertad en la red 2019] anotó la creciente violación de los derechos de los usuarios debido a acciones de vigilancia, hackeo y ciberataques, entre otras. El reporte del Índice Global de Impunidad del Comité para la Protección de los Periodistas afirmó que "Filipinas se ha colocado entre los cinco peores países prácticamente cada año desde que el índice se publicó por primera vez en 2008” (CPJ 2019).

Varias leyes (la Ley para la Prevención de los Ciberdelitos de 2012, así como los artículos 152 y 154 del Código Penal modificado) ampliaron las acciones, los discursos y los tipos de expresión que se criminalizan. La primera y la segunda leyes Bayanihan criminalizan la creación o la difusión de información falsa en relación con la crisis de covid-19 en las redes sociales y otras plataformas.

\footnotetext{
${ }^{13}$ De acuerdo con la Red Popular Kalikasan para el Medio Ambiente, alrededor de 272 defensores del medio ambiente murieron asesinados entre 2001 y 2019 (Zoledziowski y Gutierrez 2020).
} 
La segunda ley de emergencia se ha utilizado para aminorar las quejas durante la pandemia y también para perseguir a opositores y activistas políticos (Sochua 2020). Se acusó de sedición a siete activistas que distribuyeron ayuda alimentaria durante la cuarentena porque también estaban repartiendo panfletos informativos (Conde 2020). Los ciudadanos comunes que comparten su opinión personal también pueden ser acusados de ciberdifamación. ${ }^{14}$

El caso más conocido de ciberdifamación es el de Maria Ressa y Rey Santos, Jr., a quienes se imputó por un reporte de investigación sobre las actividades supuestamente corruptas de un empresario llamado Wilfredo Keng. No importó que la supuesta difamación ocurriera antes de la aprobación de la ley (Barron 2020). Este último es simplemente uno de muchos intentos del gobierno por clausurar Rappler, un sitio de noticias muy influyente que Ressa dirige.

Si estas tácticas no funcionan, el gobierno tiene otras armas. El canal más grande del país, que cuenta con una audiencia de $42 \%$, ABS-CBN, cerró poco después de la aprobación de la Ley Antiterrorista. La Cámara de Diputados no renovó su concesión y la empresa se vio obligada a despedir a 11000 empleados durante la pandemia. La última vez que ABS-CBN cerró fue con el inicio de la ley marcial de 1972.

Otros periodistas de medios de comunicación más pequeños han reportado incidentes de hostigamiento y ataques físicos supuestamente instigados por el gobierno, incluyendo un intento de homicidio. El Centro para la Libertad y la Responsabilidad de los Medios ha registrado 171 incidentes de amenazas contra la prensa desde junio de 2016, "80 de los cuales [...] fueron perpetrados por agentes del Estado" (CMFR 2020).

Sin embargo, el gobierno parece estar sentando las bases para dominar a los medios con el pretexto de la educación pública. En su informe a la nación de 2020, Duterte afirmó que el gobierno debe brindar "educación de calidad ininterrumpida a nuestros niños en la transición al aprendizaje electrónico" durante esta pandemia. Declaró que las "frecuencias de televisión que se habían devuelto al gobierno" [como las de ABS-CBN] no se restituirán

\footnotetext{
${ }^{14}$ Éste es el caso de la TFE en Taiwán, que criticó al gobierno de Duterte. La Secretaría del Trabajo y el Empleo (STE) filipina exigió que el gobierno taiwanés deportara a la TFE que hizo comentarios "repugnantes y malévolos" sobre Duterte, a lo que Taiwán se negó, afirmando que ella goza de libertad de expresión en su país (Palatino 2020c).
} 
para el uso de "particulares ni de [sus] títeres". En lugar de ello, el gabinete desarrollará "un programa y mecanismo de implementación integrado para asegurar que el gobierno utilice plenamente estas frecuencias de televisión a través de las instalaciones de PTV4 para el máximo beneficio del pueblo filipino".

\section{La Ley Antiterrorista}

La Ley Antiterrorista que se promulgó en julio es más draconiana que la Ley de Seguridad Humana de 2007 que derogó. A la fecha, una amplia gama de grupos ha presentado 35 peticiones para impugnar la ley — grupos civiles y religiosos, partidos políticos de oposición, profesores universitarios, sindicatos, ministros de justicia retirados, periodistas, grupos de jóvenes, residentes de Bangsamoro, grupos de mujeres, de indígenas y organizaciones no gubernamentales y de defensoría. Las siguientes son las características más problemáticas de la ley.

La definición de terrorismo y de "incitación al terrorismo" es tan "excesivamente amplia y vaga" que podría criminalizar cualquier tipo de discurso o expresión pronunciado dentro o fuera del país. Asimismo, la ley permite detenciones de 14 días sin mediar orden judicial, que pueden prorrogarse 10 días más de ser necesario. A diferencia de lo que establecía la Ley de Seguridad Humana, ya no es necesaria la vigilancia. Una orden preliminar de proscripción puede otorgarse dentro de un plazo de 72 horas posteriores a la presentación de una solicitud. Así, es posible declarar que una persona o una organización son terroristas sin previa audiencia desde el inicio del proceso. Por último, un cuerpo no judicial llamado Consejo Antiterrorismo supervisa esta operación. El director del Consejo es el secretario ejecutivo del presidente y el vicedirector será el consejero de Seguridad Nacional. El resto del Consejo estará conformado por las secretarías de Relaciones Exteriores, de la Defensa Nacional, de Gobierno Local, de Finanzas, de Justicia y de Tecnología de la Información y la Comunicación. El director ejecutivo del Consejo contra el Lavado de Dinero fungirá como secretario. El objetivo del Consejo es garantizar juicios expeditos, monitorear los procesos de investigación y adoptar planes de contraterrorismo. Según las Normas y Disposiciones de Implementación de la ley, el Consejo puede declarar 
que una persona es terrorista con base en "motivos de sospecha razonables", un estándar menor que la causa probable.

\section{Victimas invisibles}

Aún hay más víctimas de todo este caos, como los desplazados por la erupción del volcán Taal y por los tifones, los reos, los internos de programas de rehabilitación y los niños. Los hijos de los sospechosos de uso o venta de drogas no sólo enfrentan dificultades económicas, sino que también sufren de trauma psicológico, acoso social y estigmatización. Además, los confinamientos han triplicado los casos de abuso sexual infantil en el país, que ascendieron a 279166 del $1^{\circ}$ al 24 de mayo. Incluso si se rescata a algunas víctimas, la mayoría de los albergues están llenos y la mayor parte no acepta a varones sobrevivientes mayores de 18 años de edad (Redfern 2020; Wongsamuth 2020).

\section{No hay aliados}

La Corte Penal Internacional se encuentra investigando la guerra contra las drogas a pesar de que Filipinas se retiró del estatuto de Roma en 2018. En junio de 2020, Naciones Unidas publicó el reporte del Alto Comisionado para los Derechos Humanos sobre la situación de los derechos humanos en el país. Dicho reporte fue muy completo y resultó incriminatorio para el gobierno de Duterte. Infortunadamente, la resolución del Comité sólo propuso que hubiera "cooperación técnica y desarrollo de capacidades para la promoción y la protección de los derechos humanos en Filipinas". ${ }^{15}$ La declaración conjunta de la CFDH y otros grupos afirmó que lo anterior fue un "fracaso colectivo" del Consejo, citando la necesidad de una respuesta más robusta puesto que "un enfoque basado únicamente en la cooperación técnica y el desarrollo de capacidades no tiene posibilidades realistas de generar un impacto significativo ante un gobierno que niega la verdadera escala y gravedad de las violaciones a los derechos humanos, que ha respaldado públicamente la política de homicidios, que evita

\footnotetext{
${ }^{15}$ United Nations Human Rights Council Resolution 45/33, Technical Cooperation and Capacity-Building for the Promotion and Protection of Human Rights in the Philippines. 13 de octubre de 2020. Disponible en https://undocs.org/ en/A/HRC/RES/45/33
} 
las investigaciones independientes y sigue reprimiendo a la sociedad civil" (Human Rights Watch 2020).

\section{REGIÓN AUTÓNOMA DE BANGSAMORO DEL Mindanao Musulmán (RABMM)}

La nueva región autónoma celebró su primer año de existencia en plena pandemia. Contra todo pronóstico, la RABMM formó un gobierno de transición, elaboró un proyecto de presupuesto regional y comenzó el proceso de retirar a los combatientes y establecer un sistema de tribunales basado en la sharía. Asimismo, promulgó un Código Administrativo, el primero de seis códigos prioritarios, y presentó otros dos: el de Servicio Público y el de Gobierno Local. El Frente Moro de Liberación Islámica (FMLI) se encuentra en una lenta transición para convertirse en un partido político. La RABMM también tomó medidas para modernizar su industria marítima, brindar becas educativas y de capacitación y apuntalar sus sistemas de salud debido a la pandemia.

Sin embargo, los desafíos permanecen y los funcionarios de la RABMM solicitaron una prórroga de la Autoridad de Transición de la RABMM (ATR). Algunos de esos desafíos clave son la falta de experiencia en gobernanza pública, el prolongado periodo que se requiere para institucionalizar las normas democráticas y el cumplimiento del FMLI y el Frente Moro de Liberación Nacional (FMLN) de su acuerdo de compartición de poder (Abuza y Lischin 2020). Los funcionarios de la RABMM también deben delinear las funciones de sus instituciones de cara al gobierno nacional para evitar problemas como el tiroteo contra cuatro soldados por parte de oficiales de la policía en Sulu (CNN Philippines Staff 2020a).

La RABMM también debe asegurar que las rivalidades y las desavenencias no se vuelvan violentas. En marzo, las luchas entre clanes causaron el desplazamiento de 26300 personas, con lo que el número de desplazados internos ascendió a 370000 personas en su región. No hay espacio para el distanciamiento social en los centros para evacuados. Además, algunas familias se ven obligadas a evacuar varias veces al mes, lo que contribuye al sentido de incertidumbre en la zona. El Ministerio de Orden y Seguridad Públicos ha realizado asambleas consultivas sobre resolución de conflictos con este propósito (Saiden 2020). La 
RABMM también debe mantenerse alerta frente a grupos militantes escindidos, como los Luchadores por la Libertad Islámica de Bangsamoro (LLIB), afiliado a ISIS, el grupo proDaesh Maúte, que fue el blanco del asedio de 2017, el Grupo Abu Sayyaf y Ansar Khalifa Filipinas.

Quizá el mayor desafío es la posible falta de recursos para la economía de la RABMM debido a la pandemia. Para fines de junio, la tasa de inflación estaba entre $1 \%$ y $2 \%$ en sus seis provincias. De acuerdo con la Autoridad Filipina de Estadística, la RABMM tiene la tasa de desempleo más alta del país, 29.8\%. Además, casi 60\% de los jóvenes (o 711 800) en la RABMM provienen de familias pobres.

\section{El futuro de Marawi}

Tres años después del asedio de Marawi, la ciudad aún no queda rehabilitada del todo debido a la inercia burocrática. Un monto aproximado de ocho millones de dólares se devolvió al gobierno nacional porque no se desembolsó a tiempo (Umel 2020). Después de ello, la Secretaría de Presupuesto y Gestión liberó fondos destinados al nuevo puerto de la ciudad de Marawi (de Vera 2020) y la Fuerza de Tareas Bangon Marawi (Levántate, Marawi) confía en que $80 \%$ de sus proyectos quedarán concluidos para mediados de 2021 (Gallardo 2020).

Sin embargo, la gente aún ruega poder volver a casa (Arguillas 2020a). Para el mes de octubre, pobladores de 24 aldeas de las zonas más afectadas (MAA) por el conflicto aún no habían podido volver a sus hogares (Aben 2020). De acuerdo con la organización Marawi Reconstruction Conflict Watch [Observatorio de Conflictos en la Reconstrucción de Marawi], la liberación no es real puesto que no han podido reconstruir su vida. "No se nos ha dado compensación alguna por los daños a nuestra propiedad personal. Miles de nosotros seguimos en albergues y vivienda de interés social en condiciones terribles, con carencias de saneamiento y de servicios básicos" (Gallardo 2020). La organización Levántate, Marawi y el Plan Maestro de Desarrollo también han sido criticados por dar prioridad a los complejos, parques y restaurantes de la aldea sobre la reconstrucción de los hogares (Aben 2020).

Los locales tienen motivos para ser escépticos. El Programa de Recuperación, Rehabilitación y Reconstrucción de Marawi (PRRRM) eliminó muchos hogares, a pesar de 
que había asegurado que no emprendería esta destrucción (Jimenez-David 2020). Se presentó la iniciativa de la Ley de Compensación por el Asedio de Marawi, que sigue su trayectoria en la Cámara de Diputados (R. Cruz 2020). La intención de la iniciativa es compensar a los desplazados internos por la guerra y a quienes perdieron su hogar debido al PRRRM. Sin embargo, será difícil determinar el valor justo de mercado porque el gobierno local no había realizado levantamientos catastrales antes del asedio. Además, las coordenadas de los títulos de propiedad de los terrenos pueden ser diferentes a las coordenadas de las ubicaciones reales. Resolver este problema tomará años (Arguillas 2020b).

Además, está el tema de la rendición de cuentas por las violaciones a los derechos humanos que se cometieron durante el periodo de ley marcial, que duró tres años. Durante ese tiempo, varios defensores del medio ambiente, agricultores y funcionarios locales murieron asesinados a manos de las Fuerzas Armadas, que afirmaban que las víctimas eran miembros del Nuevo Ejército Popular, de orientación comunista. La administración de Duterte continúa obstaculizando los esfuerzos de las organizaciones internacionales por investigar esta afirmación (Aspinwall 2020).

\section{Terrorismo}

En agosto, la facción Hatib Hajan Sawadjaan del grupo Abu Sayyaf, que apoya al Estado Islámico, llevó a cabo un bombardeo suicida en Jolo. En este ataque del grupo, el quinto a la fecha, 14 personas murieron y 75 resultaron heridas. "Un reporte trimestral del Inspector General Líder de la Operación Águila del Pacífico-Filipinas [OPE-P, por sus siglas en inglés] ${ }^{16}$ que cubre el periodo de octubre a diciembre de 2019, nota que el EI ha mantenido y aumentado el reclutamiento entre los desplazados internos de la ciudad de Marawi" (Acosta 2020). Los informes de inteligencia militar y policial afirman que ha habido 700 ataques mortales y 588 avistamientos de grupos del EI durante la pandemia. Uno de estos ataques se llevó a cabo en abril, cuando "40 militantes emboscaron a soldados filipinos en la isla de Jolo, tras lo cual doce murieron y trece resultaron heridos" (Yeo y Mahzam 2020). Por tanto, Duterte ha ordenado al ejército que permanezca y construya campos militares en Marawi a

\footnotetext{
${ }^{16}$ Programa de contraterrorismo de Estados Unidos en Filipinas.
} 
pesar de una petición que firmaron 100000 maranaos de Marawi y Lanao del Sur contra la presencia militar (Esguerra 2020b; Gotinga 2019).

\section{POPULARIDAD ENTRE PROTESTAS}

Uno de los enigmas más grandes es cómo Duterte puede mantener índices de aprobación en máximos históricos entre todas las clases socioeconómicas, edades y regiones del país, a pesar de las debilidades de su gobierno. En la encuesta de Pulse Asia de septiembre de 2020, su tasa de aprobación era de 91\%. Otra encuesta de sws reportó que la mayoría de los respondientes consideraba que la respuesta del gobierno ante la pandemia era adecuada, a diferencia de la ayuda para los desempleados (SWS 2020b). Lo que resulta significativo es el hecho de que estas encuestas se cuestionaron abiertamente (Madarang 2020). Algunos analistas opinaron que los altos índices de aprobación pueden deberse al efecto de "agruparse en torno a la bandera" que se presenta en situaciones de crisis, mientras que otros consideraron que sus informes televisados de los lunes por la noche pudieron haberlo impulsado, o bien, que podría tratarse simplemente de miedo (Elemia 2020).

Ya en 2019, sws había encontrado que 51\% de los filipinos están de acuerdo en que es peligroso publicar o transmitir críticas al gobierno (Tomacruz 2019). En junio, 83\% de los respondientes dijeron que su calidad de vida había empeorado en comparación con el año anterior; en julio, $21 \%$ de los respondientes (que corresponde aproximadamente a 5.2 millones de personas) sufrían de hambre involuntaria, mientras que en septiembre $86 \%$ de los respondientes seguían estresados debido a la covid-19 (sws 2020a).

Además, los índices de popularidad no pueden explicar las protestas contra la administración que se han llevado a cabo en público y en internet. Con base en los datos disponibles, esta autora calcula que hubo alrededor de 25 protestas en 2020 y un total de 180 desde 2016. Los motivos de las manifestaciones fueron desde el perdón de un soldado estadunidense que asesinó a una filipina a la aprobación de la Ley Antiterrorista, de la intrusión a terrenos ancestrales a la pérdida de los modos de sustento. Muchas de las protestas fueron presenciales, sobre todo las manifestaciones contra las mineras o las del Día del trabajo (Villanueva 2020; Palatino 2020a; The Star 2020). 
También hubo protestas con ruido, como en el mes de julio, contra el cierre de ABSCBN y en abril, contra la lentitud en la provisión de la ayuda alimentaria (Rappler 2020a; Molina, Canofre y Palatino 2020). Una de las características distintivas de las protestas actuales es que se llevan a cabo en diversas zonas del país al mismo tiempo. Una de las expresiones más impresionantes de la indignación pública fueron las manifestaciones simultáneas en todo el país durante el informe de gobierno del presidente. Se trató de reuniones pacíficas y con distanciamiento social que combinaron el arte con la protesta en algunos casos. Hubo manifestaciones cuando menos en nueve ciudades del territorio nacional. Eran "grupos de mujeres, estudiantes, pueblos indígenas, campesinos, trabajadores, personas pobres de medios urbanos, religiosos, líderes empresariales y académicos" (Rappler 2020b). Se manifestaban en contra de la Ley Antiterrorista y las violaciones a los derechos humanos, clamaban por la libertad de prensa y "un sistema educativo incluyente", transporte justo, su modo de sustento, pruebas gratuitas a nivel masivo, los derechos de los pueblos indígenas y rendición de cuentas por el abandono de los pobres de las ciudades.

Sin embargo, las protestas que quizá han sido más significativas han tenido lugar en las redes sociales. Después de los comentarios insensibles de Duterte sobre el sufrimiento de la gente en los confinamientos, el hashtag \#OustDuterteNow [DerrocarADuterteAhora] fue tendencia en todo el mundo, con 300000 a 500000 tuits (Esguerra 2020a; Tomacruz y Hapal 2020). De acuerdo con Graphika, un análisis de estos tuits mostró que se trató de un movimiento orgánico “con pocos signos de manipulación”. Los grupos de interés fueron muy diversos —desde música K-pop filipina hasta cantantes de pop occidentales, grupos LGBT y aficionados a la música. Además, lograron opacar los tuits de Mocha Uson, conocida por difundir desinformación, así como los de otros partidarios o bots de Duterte. Varios grupos se prepararon para movilizar protestas el 30 de noviembre (día del natalicio de Bonifacio) y el 10 de diciembre (el Día Internacional de los Derechos Humanos).

\section{SEGURIDAD HUMANA}

La resolución 66/290 (2012) de la Asamblea General afirmaba que el “entendimiento común” del concepto de la seguridad humana incluye "el derecho de las personas a vivir en libertad y con dignidad, libres de la pobreza y la desesperación" y que "Todas las personas, en 
particular las vulnerables, tienen derecho a vivir libres del temor y la miseria, a disponer de iguales oportunidades para disfrutar de todos sus derechos y a desarrollar plenamente su potencial humano". La resolución también instó a los gobiernos a abstenerse de usar la fuerza pública contra sus ciudadanos y a crear políticas "centradas en las personas, exhaustivas, adaptadas a cada contexto y orientadas a la prevención”, teniendo en mente la “interrelación de la paz, el desarrollo y los derechos humanos, y tiene en cuenta igualmente los derechos civiles, políticos, económicos, sociales y culturales". ${ }^{17}$ La administración de Duterte ha fracasado de acuerdo con estas métricas.

La consolidación del poder de Duterte es una notable hazaña que no se había visto desde los tiempos del fallecido presidente Fernando Marcos. En combinación con el control de los tres poderes de gobierno y las leyes orientadas a silenciar el disenso, en Filipinas no existen las condiciones sociopolíticas para la seguridad humana. No se han propuesto soluciones a largo plazo para las ineficiencias económicas, el soborno, la corrupción, la desigualdad en los niveles de ingreso y las capacidades sanitarias del país. La política exterior filipina es una sombra de lo que solía ser y el país debe prepararse para posibles reducciones en la ayuda que proporciona Estados Unidos debido a las violaciones a los derechos humanos. Se está acotando el espacio para el disenso público y el cierre de un importante canal de noticias es alarmante. La RABMM está luchando por ponerse de pie, pero el gobierno nacional está demasiado distraído para proporcionar apoyo adecuado, y además hay signos de radicalización. La respuesta del gobierno para todo aquello que aqueja al país es el uso de la fuerza y del ejército. Sin embargo, las balas no alimentan a la gente ni detienen los virus. El gobierno insiste en continuar con sus proyectos de infraestructura y actividades relacionadas con la vigilancia, la guerra contra las drogas, la contrainsurgencia y el antiterrorismo. Estos objetivos se ponen de manifiesto en la propuesta de presupuesto del gobierno para 2021.

El gobierno propone asignar 37\% de los fondos a servicios sociales, 30\% a servicios económicos, $16 \%$ a servicios públicos en general, y $4.67 \%$ a la defensa. Un análisis más detallado del presupuesto muestra que las cifras son engañosas. Se propone que el gasto en infraestructura, que se clasifica bajo servicios económicos, ascienda a $\$ 15.7$ millones, una

\footnotetext{
${ }^{17}$ https://www.un.org/en/ga/search/view doc.asp?symbol=A/RES/66/290
} 
cifra mucho más elevada que los $\$ 8$ millones asignados a seguridad social, bienestar y empleo. El orden y la seguridad pública recibirán \$6.6 millones, mientras que la salud sólo recibirá $\$ 4.4$ millones, lo cual resulta sorprendente dado que el país aún tiene mucho camino por recorrer en el desarrollo de sus capacidades sanitarias. Es evidente que la seguridad humana no es una prioridad para el actual gobierno filipino, y nunca lo será.

Traducción: María Capetillo Lozano

Maria Ortuoste es profesora de ciencias políticas en la Universidad del Estado de California, East Bay, donde también funge como directora de su departamento. La doctora Ortuoste cursó el doctorado en la Universidad del Estado de Arizona, y su maestría y licenciatura en la Universidad de Filipinas. Ha recibido premios de la Universidad de Uppsala y el AsiaPacific Center for Security Studies [Centro de Estudios de Seguridad para Asia y el Pacífico]. Sus publicaciones más recientes son "Air Power in Southeast Asia" [Poder aéreo en el Sureste Asiático] (coautora), "Maritime Security Challenges in Southeast Asia" [Desafíos de seguridad marítima en el Sureste Asiático], "Timor-Leste and ASEAN. From Enmity to Amity, Exclusion to Semi-Inclusion" [Timor oriental y la ASEAN. De la enemistad a la amistad, de la exclusión a la semiinclusión] y "The ASEAN Regional Forum as a Strategic Waypoint: A Long View of the Forum's 25-Year Journey" [El Foro Regional de la ASEAN como punto de referencia estratégico. Una perspectiva a largo plazo de la trayectoria de 25 años del Foro]. Sus temas de investigación actuales son la relación entre la construcción de regiones y la construcción de Estados, el cine como representación del trauma genocida y su impacto en la reconstrucción de la comunidad y el papel de las conceptualizaciones del espacio marítimo en la identidad nacional. 


\section{REFERENCIAS}

Aben, Ellie. 2020. "Homesick Marawi Residents Yearn to Rebuild Lives as Philippines Rebuilds City." Arab News, octubre 20, 2020. https://www.arabnews.com/ node/1751706/world

Abrigo, Michael R. M., Jhanna Uy, Nel Jason Haw, Valerie Gilbert T. Ulep y Cris FranciscoAbrigo. 2020. "Projected Disease Transmission, Health System Requirements, and Macroeconomic Impacts of the Coronavirus Disease 2019 (Covid-19) in the Philippines.” 2020-15. PIDS Discussion Paper Series. Quezon: Philippine Institute for Development Studies.

ABS-CBN News. 2020. "Philippines Confirms First Case of New Coronavirus." ABS-CBN News, enero 30, 2020. https://news.abs-cbn.com/news/01/30/20/philippinesconfirms-first-case-of-new-coronavirus

Abuza, Zachary y Luke Lischin. 2020. “The Challenges Facing the Philippines' Bangsamoro Autonomous Region at One Year." Reporte especial. Washington, D.C.: United States Institute of Peace. https://www.usip.org/publications/2020/06/challengesfacing-philippines-bangsamoro-autonomous-region-one-year

Acosta, Rene. 2020. "Marawi Rehab Delays May Fan IS Mindanao Resurgence.” Business Mirror, febrero 14, 2020. https://businessmirror.com.ph/2020/02/14/marawi-rehabdelays-may-fan-is-mindanao-resurgence/

Agcaoili, Lawrence. 2020. "Philippine Jobless Rate Highest in Southeast Asia." Philstar.Com, agosto 13, 2020. https://www.philstar.com/business/2020/08/13/ 2034814/philippine-jobless-rate-highest-southeast-asia

AMTI. 2020. "Chinese Power Projection Capabilities in the South China Sea." Asia Maritime Transparency Initiative. https://amti.csis.org/chinese-power-projection/

Arguillas, Carolyn O. 2020a. "Marawi's Displaced Ask Senators: 'Let Us Go Home'; Appeal for Electricity, Water and Financial Assistance to Repair Houses." MindaNews (blog), febrero 21, 2020. https://www.mindanews.com/top-stories/2020/02/marawis- 
displaced-ask-senators-let-us-go-home-appeal-for-electricity-water-and-financialassistance-to-repair-houses/

Arguillas, Carolyn O. 2020b. 'Marawi Rehab Update: Senate Hearing's 'Final Solution': Meet with President Duterte." MindaNews (blog), febrero 22, 2020. https://www. mindanews.com/top-stories/2020/02/marawi-rehab-update-senate-hearings-finalsolution-meet-with-president-duterte1/

ASEAN Post Team. 2019. "Duterte's 'Build Build Build' under Fire.” The ASEAN Post, noviembre 19, 2020. https://theaseanpost.com/article/dutertes-build-build-buildunder-fire

Aspinwall, Nick. 2020. "Martial Law Lifted in Philippine South, But Military Presence Persists." The News Lens International Edition, enero 8, 2020. https://international. thenewslens.com/article/129759

Atienza, Maria Ela L. 2020. "The Philippines in 2019: Consolidation of Power, Unravelling of the Reform Agenda." Asian Survey 60 (1): 132-139. https://doi.org/10.1525/ as.2020.60.1.132

Barron, Laignee. 2020. "Maria Ressa Convicted of Cyber Libel in Philippines.” Time, junio 15, 2020. https://time.com/5853556/maria-ressa-rappler-cyber-libel-philippines/

Bisenio, Xandra Liza C. 2020. "Promised SAP Zapped." IBON Foundation (blog), agosto 18, 2020. https://www.ibon.org/promised-sap-zapped/

Bueza, Michael. 2019. " $18^{\text {th }}$ Congress, by the Numbers." Rappler, julio 2, 2019. https:// www.rappler.com/newsbreak/iq/numbers-composition-18th-congress-philippines

Bueza, Michael y Glenda Marie Castro. 2019. "MAP: Major Political Families in PH after the 2019 Elections." Rappler, agosto 30, 2019. https://www.rappler.com/newsbreak/indepth/map-major-political-families-philippines-after-elections-2019

Cabato, Regine. 2020. "Duterte Turns to Drug War Tactics to Fight Pandemic in the Philippines." Washington Post, julio 28, 2020. https://www.washingtonpost.com/ world/asia pacific/duterte-turns-to-drug-war-tactics-to-fight-pandemic-in-thephilippines/2020/07/28/7f1dfbda-ca67-11ea-99b0-8426e26d203b_story.html 
Casayuran, Mario. 2020. "Gatchalian Downplays POGO Contribution to Economy." Manila Bulletin, marzo 5, 2020. https://mb.com.ph/2020/03/05/gatchalian-downplays-pogocontribution-to-economy/

Chikiamco, Calixto V. 2020. "The Perfect Storm: Why the Philippines Faces Prolonged Economic Pain.” Business World, noviembre 1, 2020. https://www.bworldonline. com/the-perfect-storm-why-the-philippines-faces-prolonged-economic-pain/

CMFR. 2020. "Alternative News Orgs File Complaints vs State Agents before CHR." Center for Media Freedom and Responsibility, agosto 3, 2020. https://cmfr-phil.org/pressfreedom-protection/alternative-news-orgs-file-complaints-vs-state-agents-before$\underline{\mathrm{chr} /}$

CNN Philippines Staff. 2020a. "Four Soldiers Dead in Jolo 'shooting' Incident with PNP." CNN, junio 29, 2020. https://www.cnnphilippines.com/news/2020/6/29/soldiersdead-jolo-sulu-police.html

CNN Philippines Staff. 2020b. "France, Germany, UK Recognize PH Win vs. China in South China Sea Row.” CNN, septiembre 18, 2020. https://cnnphilippines.com/news/ 2020/9/18/France-Germany-United-Kingdom-reject-China-South-China-Sea.html

Conde, Carlos H. 2020. "Philippine Activists Charged with Sedition, 'Fake News'." Human Rights Watch, abril 22, 2020. https://www.hrw.org/news/2020/04/22/philippineactivists-charged-sedition-fake-news

CPJ. 2019. "Getting Away with Murder.” Committee to Protect Journalists (blog), octubre 29, 2020. https://cpj.org/reports/2019/10/getting-away-with-murder-killed-justice/

Cruz, Maricel. 2020. "Sara, Discontent Shift Tide to Lord -Manila Standard Mobile." Manila Standard, octubre 15, 2020. https://manilastandard.net/news/topstories/336842/sara-discontent-shift-tide-to-lord.html

Cruz, RG. 2020. "House Panel OKs Proposed 'Marawi Siege Compensation Act'.” ABS-CBN News, septiembre 3, 2020. https://news.abs-cbn.com/news/09/03/20/house-paneloks-proposed-marawi-siege-compensation-act 
Dayrit, Manuel M., Liezel Lagrada, Oscar F. Picazo, Melahi C. Pons y Mario C. Villaverde. 2018. “The Philippines Health System Review." Health Systems in Transition 2, WHO Regional Office for Southeast Asia: World Health Organization.

Dela Cruz, Enrico y Neil Jerome Morales. 2020. "Philippines Suffers First Recession in 29 Years, Braces for Grim Year on Virus Woes.” Reuters, agosto 6, 2020. https:// www.reuters.com/article/us-philippines-economy-gdp-idUSKCN25208X

Depasupil, William B. 2020. "Displaced OFWs to Get Cash Aid.” The Manila Times, marzo 26, 2020. https://www.manilatimes.net/2020/03/26/news/top-stories/displaced-ofwsto-get-cash-aid/706473/

Dreyer, Mallory y Kaleb Nygaard. 2020. “The Philippines Provides Support to Workers in the Informal Economy." Yale School of Management, mayo 13, 2020. https:// som.yale.edu/blog/the-philippines-provides-support-to-workers-in-the-informaleconomy

Elemia, Camille. 2020. “EXPLAINER: Duterte’s High Ratings despite Poor Covid-19 Response.” Rappler, octubre 5, 2020. https://www.rappler.com/newsbreak/ explainers/explainers-reasons-duterte-high-ratings-poor-covid-19-response

Esguerra, Darryl John. 2020a. “\#OustDuterte Trends as Gov’t Belies 'Relaxed’ Approach to NCoV Scare.” INQUIRER.Net, enero 31, 2020. https://newsinfo.inquirer.net/ $\underline{1222383 / a s-o u s t d u t e r t e-t r e n d s-p a l a c e-d e n i e s-g o v t-r e l a x i n g-o n-n o v e l-c o r o n a v i r u s-~}$ scare

Esguerra, Darryl John. 2020b. “Amid Rehab Efforts, Duterte Orders Military to Maintain Presence in Marawi City | Inquirer News.” INQUIRER.Net, marzo 5, 2020. https:// newsinfo.inquirer.net/1237341/amid-rehab-efforts-duterte-says-military-tomaintain-presence-in-marawi-city

Esguerra, Darryl John. 2020c. "On 4th Anniversary of Arbitral Win vs China, PH Insists Award 'Non-Negotiable'." INQUIRER.Net, julio 12, 2020. https://globalnation. inquirer.net/189412/on-4th-anniversary-of-arbitral-win-vs-china-ph-insists-award$\underline{\text { non-negotiable }}$ 
Esguerra, Darryl John. 2020d. "No More Covid-19 Test for Returning OFWs from Low-Risk Countries.” INQUIRER.Net, octubre 19, 2020. https://newsinfo.inquirer.net/ $\underline{1349712 / \text { no-more-covid-19-test-for-returning-ofws-from-low-risk-countries-doh }}$

Gagalac, Ron. 2019. "P700 Billion Lost Yearly Due to Corruption, Says Official.” ABS-CBN News, agosto 15, 2020. https://news.abs-cbn.com/news/08/15/19/p700-billion-lostyearly-due-to-corruption-says-official

Gallardo, Froilan. 2020. “80\% of Marawi Rehab Completed by Mid-July 2021, Says TFBM’s Del Rosario." MindaNews (blog), octubre 18, 2020. https://www.mindanews. com/top-stories/2020/10/80-of-marawi-rehab-completed-by-mid-july-2021-saystfbms-del-rosario/

Gita-Carlos, Ruth Abbey. 2020. "PH Eyes Diplomatic Means to Resolve SCS Dispute: Palace." Philippine News Agency, julio 15, 2020. https://www.pna.gov.ph/ $\underline{\operatorname{articles} / 1109018}$

Gonzales, Maria Lourdes. 2018. "Size of the Informal Economy in the Philippines." Presentado en ILO Enterprise Formalization, Makati, julio 16, 2018. https://www.ilo. org/manila/eventsandmeetings/WCMS 634914/lang--en/index.htm

Gotinga, JG. 2019. “100,000 Maranao Sign Petition to Halt Planned Military Camps in Marawi." Rappler, noviembre 18, 2019. https://www.rappler.com/nation/maranaopetition-halt-military-camps-marawi

Gutierrez, Margarita. 2020. “Accredited Service Providers Association of Pagcor Reacts to Carpio: No 'Invisible Hand' in Pogos.” INQUIRER.Net, mayo 29, 2020. https:// opinion.inquirer.net/130240/accredited-service-providers-association-of-pagcorreacts-to-carpio-no-invisible-hand-in-pogos

Heydarian, Richard Javad. 2020. “Chinese Casinos Spark Viral Uproar in Philippines.” Asia Times, mayo 14, 2020. https://asiatimes.com/2020/05/chinese-casinos-spark-viraluproar-in-philippines/ 
Human Rights Watch. 2020. "Philippines: Human Rights Council Joint NGO Statement." Human Rights Watch, octubre 6, 2020. https://www.hrw.org/news/2020/10/06/ philippines-human-rights-council-joint-ngo-statement

Huong, Le Thu y Alexandra Pascoe. 2020. “This Is No Time to Take Eyes off the South China Sea.” The Strategist, julio 6, 2020. https://www.aspistrategist.org.au/this-is-notime-to-take-eyes-off-the-south-china-sea/

IBON Media \& Communications. 2020. "Proposed 2021 Health Budget Shrinks, Neglects Public Health-IBON." IBON Foundation (blog), septiembre 22, 2020. https://www.ibon.org/proposed-2021-health-budget-shrinks-neglects-public-health/

Inggas, Ika y John Bechtel. 2020. "In Letter to UN Chief, Indonesia Takes Stand on South China Sea.” BenarNews, mayo 28, 2020. https://www.benarnews.org/english/news/ indonesian/unclos-letter-05282020172147.html

Inquirer Research. 2020. "Trust of Pinoys in China Falls from Poor to Bad - Sws Survey." INQUIRER.Net, julio 21, 2020. https://newsinfo.inquirer.net/1309563/trust-ofpinoys-in-china-falls-from-poor-to-bad

Jha, Preeti. 2020. "How Filipino Activists Ended up on a 'wanted' Poster.” $B B C N e w s$, octubre 6, 2020. https://www.bbc.com/news/world-asia-54144623

Jimenez-David, Rina. 2020. “Marawi a Matter of Justice.” INQUIRER.Net, mayo 27, 2020. https://opinion.inquirer.net/130190/marawi-a-matter-of-justice

Kenny, Paul D. 2019. Populism in Southeast Asia. Canberra: Australian National University Canberra.

Koh, Collin. 2020. "Asean Can No Longer Afford to Be Subtle over the South China Sea." South China Morning Post, julio 4, 2020. https:/www.scmp.com/week-asia/ opinion/article/3091775/asean-can-no-longer-afford-be-subtle-over-south-china-sea

Lagrimas, Nicole-Anne C. 2020. "Lawmaker Questions Proposed P16-B Barangay Development Program.” MSN-News, septiembre 4, 2020. https://www.msn.com/en$\mathrm{ph} /$ news/national/lawmaker-questions-proposed-p16-b-barangay-developmentprogram/ar-BB18I3xe 
Lalu, Gabriel Pabico. 2019. “113 Environmental Activists Killed since Duterte Assumed Office - Int'l Group.” INQUIRER.Net, septiembre 24, 2019. https://globalnation. inquirer.net/180127/113-environmental-activists-killed-since-duterte-assumedoffice-intl-group

Lalu, Gabriel Pabico. 2020. “Don't Push Jeepney Phaseout during Pandemic, but Help Drivers Modernize - Robredo.” INQUIRER.Net, junio 21, 2020. https://newsinfo. inquirer.net/1295280/dont-push-jeepney-phaseout-this-pandemic-help-drivers$\underline{\text { modernize-instead }}$

Lee, Yen Nee. 2020. “Four Years on, Philippine President Duterte Is Still Struggling to Show the Benefits of Being pro-China." CNBC, septiembre 8, 2020. https://www.cnbc.com/ 2020/09/08/philippine-president-duterte-fails-to-produce-results-from-pro-chinastance.html

Lim, Jose Lorenzo. 2020a. “The Shady Side of POGOs.” IBON Foundation (blog), febrero 26, 2020. https://www.ibon.org/the-shady-side-of-pogos/

Lim, Jose Lorenzo. 2020b. “On the BBB Fix: Why Do You Build Me Up?” IBON Foundation (blog), julio 11, 2020. https://www.ibon.org/on-the-bbb-fix-why-do-you-build-me$\underline{\mathrm{up} /}$

Lopez, Ditas B. y Claire Jiao. 2020. "Supplier of World's Nurses Struggles to Fight Virus at Home - Bloomberg.” Bloomberg, abril 23, 2020. https://www.bloomberg.com/news/ articles/2020-04-23/philippines-sends-nurses-around-the-world-but-lacks-them-at$\underline{\text { home }}$

Madarang, Catalina Ricci S. 2020. "Skepticism over Pulse Asia Survey on Duterte PostLockdown Performance, Approval Rating." Interaksyon, octubre 6, 2020. https://interaksyon.philstar.com/politics-issues/2020/10/06/178126/skepticismpulse-asia-duterte-performance-covid19-survey/

Magsino, Dona. 2020. “Gov’t Launches One Hospital Command for Seamless Referral of Covid-19 Patients." MSN, agosto 6, 2020. https://www.msn.com/en-ph/news/ national/gov-t-launches-one-hospital-command-for-seamless-referral-of-covid-19patients/ar-BB17CXrf 
Magsino, Dona y Erwin Colcol. 2020. “Congress Gives Duterte Authority over Budget, Operation of Medical Facilities in Fight vs. Covid-19.” GMA News Online, marzo 24, 2020. $\quad$ https://www.gmanetwork.com/news/news/nation/730983/congress-givesduterte-authority-over-budget-operation-of-medical-facilities-in-fight-vs-covid$19 /$ story/

Marquez, Consuelo. 2020. “QCPD Rounds up 20 Protesters Demanding Food Aid from Gov’t | Inquirer News." INQUIRER.Net, abril 1, 2020. https://newsinfo.inquirer.net/ $\underline{1252199 / q c p d-r o u n d s-u p-20-p r o t e s t e r s-d e m a n d i n g-f o r-f o o d-a i d ~}$

McCarthy, Julie. 2020. “The Philippine Government's Covid-19 Response Has Devastated Its Economy.” NPR.Org, julio 9, 2020. https://www.npr.org/2020/07/09/889307982/ the-philippine-governments-covid-19-response-has-devastated-its-economy

Mendiola, Ritchel. 2020. "PH among Countries to See an Increase in Extreme Poverty Due to Covid-19." Asian Journal News (blog), noviembre 11, 2020. https://www. asianjournal.com/philippines/across-the-islands/ph-among-countries-to-see-anincrease-in-extreme-poverty-due-to-covid-19/

Mercado, Neil Arwin. 2020. “Anti-POGO Bill Filed in House.” INQUIRER.Net, mayo 6, 2020. https://newsinfo.inquirer.net/1270952/anti-pogo-bill-filed-in-house

Molina, Jose Carpintero, Fernanda Canofre y Mong Palatino. 2020. "From Brazil to Kosovo to the Philippines, Confined Citizens Protest from Their Windows." Global Voices (blog), abril 14, 2020. https://globalvoices.org/2020/04/14/from-brazil-to-kosovo-tothe-philippines-confined-citizens-protest-from-their-windows/

Newsdesk. 2020. "POGOs Contributing US\$1.87 Billion to Philippine Economy Annually, Says Industry Group.” Inside Asian Gaming (blog), mayo 19, 2020. https://www. asgam.com/index.php/2020/05/20/pogos-contributing-us1-87-billion-to-philippineeconomy-annually-says-industry-group/

Noble, Luz Wendy T. 2020. “April Remittance Contraction Hits 19-Year Record.” Business World (blog), julio 16, 2020. https://www.bworldonline.com/april-remittancecontraction-hits-19-year-record/ 
O’Connor, Devin. 2020. "Philippines Offshore Gaming Revenue Sinks Amid Covid-19 Pandemic.” Casino.Org (blog), septiembre 26, 2020. https://www.casino.org/news/ $? \mathrm{p}=150062$

Olanday, Dan y Jennifer Rigby. 2020. “Inside the World's Longest and Strictest Coronavirus Lockdown in the Philippines.” The Telegraph, julio 11, 2020. https://www.telegraph. co.uk/global-health/science-and-disease/inside-worlds-longest-strictest-coronaviruslockdown-philippines/

Palatino, Mong. 2020a. "Philippine Police Dismantle Anti-Mining Barricade amid Covid-19 Lockdown.” Global Voices (blog), abril 10, 2020. https://globalvoices.org/2020/ 04/10/philippine-police-dismantle-anti-mining-barricade-amid-covid-19-lockdown/

Palatino, Mong. 2020b. "What Is Bogging Down the Philippines Covid-19 Response?” The Diplomat, abril 20, 2020. https://thediplomat.com/2020/04/what-is-bogging-downthe-philippines-covid-19-response/

Palatino, Mong. 2020c. "Taiwan Refuses to Deport Caregiver Who 'Insulted' Philippine President on Facebook." Global Voices (blog), mayo 7, 2020. https://globalvoices. org/2020/05/07/taiwan-refuses-to-deport-caregiver-who-insulted-philippinepresident-on-facebook/

PDI Editorial. 2020. “"Build, Build, Build' Woes.” INQUIRER.Net, julio 13, 2020. https://opinion.inquirer.net/131711/build-build-build-woes

Piedad, Maricar R. 2020. “Covid-19: How Prepared Are We Now?” IBON Foundation (blog), junio 6, 2020. https://www.ibon.org/covid-19-how-prepared-are-we-now/

Pompeo, Michael R. 2020. "U.S. Position on Maritime Claims in the South China Sea." United States Department of State (blog), julio 13, 2020. https://www.state.gov/u-sposition-on-maritime-claims-in-the-south-china-sea/

PSA. 2018. "2018 Family Income and Expenditure Survey: National and Regional Estimates." ISHB. Manila: Philippine Statistics Authority. https://psa.gov.ph/sites/default/files/ FIES\%202018\%20Final\%20Report.pdf 
PSA. 2020. "Total Number of OFWs Estimated at 2.2 Million.” Philippine Statistics Authority, junio 4, 2020. https://psa.gov.ph/statistics/survey/labor-and-employment/surveyoverseas-filipinos

Punongbayan, JC. 2019. "How the TRAIN Law Worsened Poverty, Inequality." Rappler, abril 25, 2019. https://www.rappler.com/voices/thought-leaders/how-tax-reform-lawworsened-poverty-inequality-philippines

Raga, Sherillyn y Dirk Willem te Velde. 2020. "Economic Vulnerabilities to Health Pandemics: Which Countries Are Most Vulnerable to the Impact of Coronavirus." Supporting Economic Transformation. Londres: Overseas Development Institute. https://set.odi.org/wp-content/uploads/2020/02/Economic-Vulnerability.pdf

Ranada, Pia y Sofia Tomacruz. 2020. "Pandemic Unravels Duterte's 2016 Promise of Decisive Leadership.” Rappler, junio 28, 2020. https://www.rappler.com/newsbreak/ in-depth/coronavirus-pandemic-unravels-duterte-2016-promise-decisive-leadership

Rappler. 2020a. "IN PHOTOS: Filipinos Make Noise Nationwide to Protest ABS-CBN Shutdown." Rappler, julio 19, 2020. https://www.rappler.com/moveph/photosfilipinos-make-noise-nationwide-protest-abs-cbn-shutdown

Rappler. 2020b. “IN PHOTOS: SONA 2020 Protests around the Philippines.” Rappler, julio 28, 2020. https://www.rappler.com/moveph/sona-2020-protests-philippines-photos

Ratcliffe, Rebecca. 2020. "Millions in Manila Back in Lockdown as Duterte Loses Control of Coronavirus Spread." The Guardian, agosto 4, 2020. http://www.theguardian. com/world/2020/aug/04/millions-in-manila-philippines-back-in-lockdown-asduterte-loses-control-of-coronavirus-spread

Redfern, Corinne. 2020. "Filipino Children Abandoned to Internet Sex Abusers during Coronavirus." The Fuller Project, julio 7, 2020. https://fullerproject.org/story/ philippines-trafficking-shelters-child-abuse/

Reuters Staff. 2020a. "Philippines' Duterte Eases Overseas Travel Ban on Health Workers." Reuters, septiembre 21, 2020. https://www.reuters.com/article/health-coronavirusphilippines-nurses-idUSL3N2GI0OB 
Reuters Staff. 2020b. “Philippines' Duterte Promises Payment as Red Cross Stops Covid-19 Tests." Reuters, octubre 23, 2020. https://www.reuters.com/article/us-healthcoronavirus-philippines-testin-idUSKBN2781J7

Rey, Aika. 2020. “In Duterte's 2021 Budget, Filipinos Are on Their Own.” Rappler, septiembre 29, 2020. https://www.rappler.com/newsbreak/in-depth/filipinos-welfare -employment-education-duterte-2021-national-budget

Rivas, Ralf. 2019. “Online Gambling Contributes P551 Billion to Philippine Economy Yearly." Rappler, septiembre 17, 2019. https://www.rappler.com/business/onlinegambling-contribution-philippine-economy-yearly

Robles, Alan. 2019. “A Chinese Crime Wave Hits Duterte's Philippines as POGOS Grow Unchecked." South China Morning Post, diciembre 27, 2019. https://www. scmp.com/week-asia/economics/article/3043542/chinese-crime-wave-hits-dutertesphilippines-pogos-grow

Robles, Alan. 2020. "Coronavirus: Philippines Capital Emerges from Lockdown into Economic Uncertainty, Fears of Second Wave of Infection." South China Morning Post, mayo 31, 2020. https://www.scmp.com/week-asia/health-environment/article/ $\underline{3086881 / \text { coronavirus-philippines-capital-emerges-lockdown }}$

Robles, Raissa. 2019. “China Promised Duterte US\$9 Billion. He’s Had Less than US\$1 Billion. Why?" South China Morning Post, octubre 26, 2019. https://www.scmp.com/ week-asia/politics/article/3034666/china-promised-duterte-us9-billioninfrastructure-hes-had-only

Robles, Raissa. 2020a. "Rodrigo Duterte's U-Turn on VFA Was Motivated by South China Sea Tensions." South China Morning Post, junio 22, 2020. https://www.scmp. com/week-asia/politics/article/3090150/philippines-foreign-secretary-says-dutertes$\underline{\text { u-turn-vfa-was }}$

Robles, Raissa. 2020b. "Duterte Rejects Revolutionary Government as Health Rumours Swirl.” South China Morning Post, agosto 25, 2020. https://www.scmp.com/weekasia/politics/article/3098826/duterte-rejects-revolutionary-government-philippineshealth 
Robles, Raissa. 2020c. "Philippines Extends Suspension of VFA Termination, Eyes LongTerm Defence Pact with US.” South China Morning Post, noviembre 11, 2020. https://www.scmp.com/week-asia/politics/article/3109445/philippines-extendssuspension-vfa-termination-eyes-long-term

Saiden, Albashir. 2020. “BARMM Conducts Consultations to Address Clan Feuds.” Philippine News Agency, junio 8, 2020. https://www.pna.gov.ph/articles/1105270

San Diego, Martin. 2019. “China Turns the Tables on Philippines' Offshore Gambling Habit." South China Morning Post, septiembre 8, 2019. https://www.scmp.com/ week-asia/politics/article/3026095/china-turns-tables-philippines-offshoregambling-habit

Septiari, Dian. 2020. “Indonesia Joins Neighbors in Protesting Beijing's Claims in South China Sea." The Jakarta Post, junio 1, 2020. https://www.thejakartapost.com/ news/2020/06/01/indonesia-joins-neighbors-in-protesting-beijings-claims-in-southchina-sea.html

Siu, Phila y Sarah Zheng. 2018. "China Holds the Cards as Online Betting Booms in the Philippines." South China Morning Post, diciembre 15, 2020. https://www. scmp.com/week-asia/geopolitics/article/2177683/china-holds-cards-online-bettingbooms-philippines

Sochua, Mu. 2020. “Coronavirus ‘Fake News’ Arrests Are Quieting Critics.” Foreign Policy (blog), mayo 22, 2020. https://foreignpolicy.com/2020/05/22/coronavirus-fakenews-arrests-quiet-critics-southeast-asia/

Stilwell, David. 2020. “The South China Sea, Southeast Asia's Patrimony, and Everybody’s Own Backyard." U.S. Embassy in Cambodia, julio 15, 2020. https://kh. usembassy.gov/the-south-china-sea-southeast-asias-patrimony-and-everybodysown-backyard/

SWS. 2020a. "SWS September 17-20, 2020 National Mobile Phone Survey - Report No. 7: Filipinos Stressed by the Covid-19 Crisis Remain High at 86\%." Social Weather Stations, octubre 8, 2020. $\underline{\text { https://www.sws.org.ph/swsmain/artcldisppage/ }}$ ? $\underline{\text { artcsyscode }=\text { ART }-20201008195826}$ 
SWS. 2020b. "SWS September 17-20, 2020 National Mobile Phone Survey - Report No. 9: Majority of Filipinos Say Government Actions against Covid-19 Are 'Adequate', except on Providing Help to the Jobless.” Social Weather Stations, octubre 12, 2020. https://www.sws.org.ph/swsmain/artcldisppage/?artcsyscode=ART$\underline{20201017195244}$

SWS. 2020c. "SWS September 17-20, 2020 National Mobile Phone Survey - Report No. 8: $71 \%$ of Filipino Families Received Money-Help from Government since the Start of the Covid-19 Crisis.” Social Weather Stations, octubre 13, 2020. https://www.sws. org.ph/swsmain/artcldisppage/?artcsyscode=ART-20201013204950

Takenaka, Aiko Kikkawa, James Villafuerte, Raymond Gaspar y Badri Narayanan. 2020. “Covid-19 Impact on International Migration, Remittances and Recipient Households in Developing Asia.” ADB Briefs. Asian Development Bank. https://www.adb.org/ sites/default/files/publication/622796/covid-19-impact-migration-remittancesasia.pdf

The Star. 2020. "Many People Arrested in May Day Protests in Philippines." The Star, mayo 2, 2020. https://www.thestar.com.my/news/regional/2020/05/02/many-poople-arrestedin-may-day-protests-in-philippines

Thompson. 2016. "The Moral Economy of Electoralism and the Rise of Populism in the Philippines and Thailand.” Journal of Developing Societies 32 (3): 246-269.

Tomacruz, Sofia. 2019. "Majority of Filipinos Think It's Dangerous to Publish Anything Critical of Duterte Admin." Rappler, agosto 3, 2019. https://www.rappler.com/ nation/majority-filipinos-think-dangerous-publish-things-critical-duterte-admin-sws

Tomacruz, Sofia y Don Kevin Hapal. 2020. “Coronavirus Response: Online Outrage Drowns out Duterte Propaganda Machine.” Rappler, abril 24, 2020. https://www.rappler. com/newsbreak/in-depth/coronavirus-response-online-outrage-drowns-dutertepropaganda-machine

Tupas, Emmanuel. 2020. “PDEA Keeping Tabs on POGOs' Link to Drug Trade.” Philippine Star, marzo 2, 2020. https://www.philstar.com/headlines/2020/03/02/1997473/pdeakeeping-tabs-pogos-link-drug-trade 
Umel, Richel V. 2020. "Philippines: Millions Earmarked for Marawi Recovery Returned to Treasury." BenarNews, enero 27, 2020. https://www.benarnews.org/english/news/ philippine/funds-returned-01272020125721.html

Vera, Ben O. de. 2020. "DBM Releases Funds to Build New Marawi City Port." INQUIRER.Net, junio 7, 2020. https://business.inquirer.net/299347/dbm-releasesfunds-to-build-new-marawi-city-port

Villanueva, Raymund B. 2020. "Philippine Art Town Unites against Mining Extension." Global Voices (blog), enero 9, 2020. https://globalvoices.org/2020/01/09/philippineart-town-unites-against-mining-extension/

Wong, Catherine. 2020. "Golden Period of China-Philippines Friendship Loses Its Shine." South China Morning Post, julio 25, 2020. https://www.scmp.com/news/china/ diplomacy/article/3094393/golden-period-china-philippines-friendship-loses-its-shine

Wongsamuth, Nanchanok. 2020. “Online Child Sex Abuse Cases Triple under Lockdown in Philippines.” Reuters, mayo 29, 2020. https://www.reuters.com/article/philippinessexcrimes-internet-idUSL8N2D94I3

World Bank Group. 2020. "Impacts of Covid-19 on Firms in the Philippines." World Bank. http://pubdocs.worldbank.org/en/201241601955900723/Results-from-thePhilippines-COVID-19-Firm-Survey-conducted-in-July-2020.pdf

Yee, Jovic. 2020. "Hospitals Running out of Covid-19 Beds - DOH.” INQUIRER.Net, julio 29, 2020. https://newsinfo.inquirer.net/1313657/doh-warns-hospitals-running-outof-covid-19-beds

Yeo, Kenneth y Remy Mahzam. 2020. “2020 Jolo Suicide Attack: Evolving Tactics.” RSIS Commentary, agosto 31, 2020. https://www.rsis.edu.sg/rsis-publication/icpvtr/2020jolo-suicide-attack-evolving-tactics/\#.X456We17mUk

Zoledziowski, Anya y Natashya Gutierrez. 2020. "Land Defenders Are Killed in the Philippines for Protesting Canadian Mining.” VICE, octubre 1, 2020. https://www. vice.com/en/article/qj4743/land-defenders-are-killed-in-the-philippines-forprotesting-canadian-mining 